\title{
Osteossíntese provisória das fraturas expostas da diáfise da tíbia com fixador externo não transfixante*
}

\author{
Provisional osteosynthesis of open diaphyseal \\ fractures of the tibia with pinless external fixator
}

José Octavio Soares Hungria ${ }^{1}$, Marcelo Tomanik MerCadante ${ }^{2}$

\section{RESUMO}

Objetivo: Avaliar a eficácia do fixador externo não transfixante como tratamento provisório das fraturas expostas Gustilo e Anderson graus I e II. Métodos: Em estudo prospectivo, 36 fraturas expostas da diáfise da tíbia foram tratadas seqüencialmente com fixador não transfixante seguido por haste intramedular maciça bloqueada não fresada. A média de idade foi de 28 anos e $88,9 \%$ dos pa-

* Trabalho desenvolvido no Programa do Curso de Pós-Graduação da Faculdade de Ciências Médicas da Santa Casa de São Paulo, agraciado com bolsa da CAPES. Realizado no Departamento de Ortopedia e Traumatologia da Santa Casa de Misericórdia de São Paulo - "Pavilhão Fernandinho Simonsen" (Diretor: Prof. Dr. Cláudio Santili).

1. Médico do Departamento de Ortopedia e Traumatologia da Santa Casa de Misericórdia de São Paulo; Médico Assistente do Grupo do Trauma; Aluno do Programa de Pós-Graduação em Medicina, na área de concentração Ortopedia e Traumatologia - Mestrado da Faculdade de Ciências Médicas da Santa Casa de São Paulo FCMSC - São Paulo (SP), Brasil.

2. Professor Adjunto do Departamento de Ortopedia e Traumatologia da Faculdade de Ciências Médicas da Santa Casa de São Paulo; Médico Chefe de Clínica do Departamento de Ortopedia e Traumatologia da Santa Casa de Misericórdia de São Paulo Hospital Central; Chefe do Grupo do Trauma - FCMSC - São Paulo (SP), Brasil.

Endereço para correspondência: Santa Casa de Misericórdia de São Paulo - Departamento de Ortopedia e Traumatologia ("Pavilhão Fernandinho Simonsen"), Rua Dr. Cesário Motta Jr., 112 - 01277-900 - São Paulo, SP. Tel.: (11) 2176-7000, r. 5449; fax: (11) 223-3380. E-mail: trauma@santacasasp.org.br

Recebido em 8/3/07. Aprovado para publicação em 24/1/08. Copyright RBO2008 cientes eram do sexo masculino. $\mathrm{O}$ mecanismo de trauma foi: acidente motociclístico em $47,1 \%$, atropelamento em $36,1 \%$. Entre os pacientes, nove $(25,0 \%)$ apresentaram lesões associadas. Segundo a classificação $\mathrm{AO}, 12$ pacientes $(33,3 \%)$ haviam sofrido fraturas do tipo A, $18(50,0 \%)$ do tipo B e seis $(16,6 \%)$ fraturas tipo C. Segundo a classificação de Gustilo e Anderson, 13 pacientes $(36,1 \%)$ eram portadores de fraturas expostas grau I e 23 $(63,9 \%)$, de fraturas grau II. O tempo médio de fixação externa foi de seis dias, variando de três a 22 dias. Resultados: Entre os pacientes, 32 evoluíram satisfatoriamente. As complicações relacionadas ao fixador existiram em quatro pacientes: em três houve impossibilidade de conversão com o fixador instalado e em um ocorreu neurapraxia do fibular superficial. Conclusão: O fixador externo não transfixante é útil como fixação provisória das fraturas expostas da diáfise da tíbia quando se visa a conversão para osteossíntese intramedular.

Descritores - Fraturas da tíbia; Fraturas expostas; Diáfises; Fixadores externos; Fixação intramedular de fraturas; Estudos prospectivos

\section{ABSTRACT}

Objective: To evaluate the effectiveness of the pinless external fixator for the provisional treatment of Gustilo and Anderson grade I and II open fractures. Methods: In a prospective study, 36 open diaphyseal fractures of the tibia were sequentially treated with a pinless fixator followed by massive, blocked, non- 
edged intramedullary nail. Mean age was 28 years, and $88.9 \%$ of the patients were male. The mechanism of trauma was: motorcycle accident in $47.1 \%$, being run over by vehicle in 36.1\%. Among the patients, 9 (25.0\%) had associated lesions. According to the AO classification, 12 patients (33.3\%) had suffered type A fractures, 18 patients (50.0\%), type B fractures, and 6 patients (16.6\%), type C fractures. According to the Gustilo and Anderson classification, 13 patients (36.1\%) had grade I opened fractures, and 23 (63.9\%) had grade II fractures. The mean time of external fixation was six days, ranging from 3 to 22 days. Results: 32 patients had a satisfactory evolution. Fixator-related complications were seen in four patients: in three, the installed fixator could not be converted, and one had surface fibular neurapraxia. Conclusion: The pinless external fixation helps as provisional fixation of open diaphyseal fractures of the tibial when the intention is to later convert to intramedullary osteosynthesis.

\section{Keywords - Tibial fractures; Open fractures; Diaphysis; External fixators, Intramedullary fracture fixation; Prospective studies}

\section{INTRODUÇÃO}

Devido ao mecanismo de trauma e à escassa cobertura cutânea ântero-medial, a tíbia é o osso longo que mais frequientemente sofre fratura exposta ${ }^{(1-6)}$. Entre as causas mais freqüentes estão os traumas de alta energia, os acidentes automobilísticos, motociclísticos e atropelamentos, além das fraturas em consequiência de ferimento por projétil de arma de fogo.

Mesmo seguindo os conceitos consagrados para o tratamento das fraturas expostas, ou seja, desbridamento cirúrgico, fixação imediata das fraturas expostas e administração de antibiótico, o tratamento das fraturas expostas da diáfise da tíbia apresenta índices não desprezíveis de complicações: infecção óssea, pseudartrose e consolidação viciosa ${ }^{(1,3,6-15)}$. Na tentativa de minimizar as taxas de infecção, a fixação das fraturas expostas da diáfise da tíbia é feita com fixador externo.

Devido ao período prolongado para consolidação da fratura e pela dificuldade em manter a interface pino- osso estável, a troca do fixador externo está freqüentemente indicada ${ }^{(7)}$. A conversão para osteossíntese interna com haste intramedular apresenta taxas elevadas de infecção quando a conversão é realizada após o uso prolongado do fixador externo ${ }^{(16)}$. A solução é a conversão precoce, antes do 14ㅇ dia de evolução, para evitar a infecção no trajeto dos pinos de Schanz e a conseqüente infecção medular ${ }^{(17)}$.

Buscando evitar as complicações infecciosas, foi idealizado pelo grupo AO o fixador externo sem pinos transfixantes $\left(\right.$ Pinless $^{\circledR}$ - Synthes AG $^{\circledR}$ ) para o tratamento inicial das fraturas expostas da diáfise da tíbia, visando a conversão para a haste intramedular bloqueada não fresada sem os riscos mencionados, com o fixador instalado mantendo a redução da fratura e facilitando a conversão $0^{(7-9,11-12,16,18-19)}$.

A tendência da literatura mundial para o tratamento das fraturas expostas da diáfise da tíbia graus I e II de Gustilo et al é a fixação imediata com haste intramedular ${ }^{(20)}$. Entretanto, tal material não está disponível na maioria dos serviços ortopédicos de emergência do Brasil, inclusive no da Santa Casa de Misericórdia de São Paulo ${ }^{(21)}$.

O objetivo deste estudo é verificar a eficácia e as complicações da opção que adotamos: o fixador externo extramedular $\left(\right.$ Pinless $\left.^{\circledR}\right)$ como tratamento provisório das fraturas expostas graus I e II da diáfise da tíbia.

Este estudo foi aprovado pelo Comitê de Ética em Pesquisa da Irmandade da Santa Casa de Misericórdia de São Paulo - CEP - ISCMSP, projeto 042/02.

\section{MÉTODOS}

No Departamento de Ortopedia e Traumatologia da Santa Casa de Misericórdia de São Paulo - "Pavilhão Fernandinho Simonsen", no período de junho de 2000 a outubro de 2005 foram tratadas 36 fraturas expostas da diáfise da tíbia em pacientes com maturidade esquelética, segundo protocolo de procedimento seqüencial para fixação externa e posterior conversão para haste intramedular.

Todos os pacientes chegaram ao Pronto-Socorro Central e, após avaliação e liberação pelas equipes de especialidades, foram encaminhados ao Departamen- 
to de Ortopedia e Traumatologia para tratamento das fraturas. Apenas um paciente necessitou tratamento cirúrgico de outra especialidade (cirurgia da cabeça e pescoço - bucomaxilofacial), operado eletivamente.

Foram incluídos no trabalho todos os pacientes adultos com fratura exposta da diáfise da tíbia graus I e II de Gustilo et al ${ }^{(20)}$, quando havia disponível o fixador externo Pinless ${ }^{\circledR}$. Foram excluídos os pacientes sem maturidade esquelética, com fraturas expostas grau III de Gustilo et $\mathrm{l}^{(20)}$ e quando não havia o fixador externo Pinless ${ }^{\circledR}$ disponível no momento da chegada do paciente ao Pronto-Socorro.

Todos os pacientes sofreram fraturas expostas grau I ou II de Gustilo et al ${ }^{(20)}$. As fraturas expostas grau III de Gustilo e Anderson foram excluídas ${ }^{(20)}$.

Dos 36 pacientes, $32(88,9 \%)$ eram do sexo masculino. A média de idade foi de 28 anos, variando de 18 a 43 anos. O lado direito foi acometido em 19 pacientes $(52,8 \%)$. Não houve relato de caso de fratura bilateral da diáfise da tíbia.

O mecanismo do trauma foi: acidente motociclístico em 17 pacientes (47,2\%), atropelamento em 13 $(36,0 \%)$, acidente automobilístico em dois $(5,6 \%)$, trauma esportivo em dois $(5,6 \%)$, queda em dois $(5,6 \%)$ (tabela 1).

TABELA 1

Distribuição dos 36 pacientes portadores de fratura exposta da diáfise da tíbia, segundo o mecanismo de trauma

\begin{tabular}{lrr}
\hline \multicolumn{1}{c}{ Mecanismo } & N & (\%) \\
\hline Acidente motociclístico & 17 & 47,2 \\
Atropelamento & 13 & 36,0 \\
Acidente automobilístico & 2 & 5,6 \\
Trauma esportivo & 2 & 5,6 \\
Queda solo & 1 & 2,8 \\
Queda altura & 1 & 2,8 \\
Total & 36 & 100,0 \\
\hline
\end{tabular}

Fonte: SAME Hospital.

Entre os pacientes, nove $(25,0 \%)$ sofreram lesões associadas: três apresentaram fraturas nas mãos; dois, fratura ipsilateral do maléolo medial; um, lesão de menisco medial e do ligamento cruzado posterior; um, fratura de face e mandíbula; um, fratura ipsilateral sem desvio do planalto tibial; e um paciente, múltiplas fraturas nos membros inferiores (fratura exposta do fêmur ipsilateral e fratura-luxação exposta do tornozelo contralateral).

Todos os pacientes foram submetidos na emergência à limpeza cirúrgica, desbridamento e instalação do fixador externo Pinless ${ }^{\circledR}$ (Synthes AG $\left.^{\circledR}\right)^{(8-13,18-19,22-24)}$, segundo a técnica proposta. Após a fixação externa, todos os pacientes permaneceram internados. Seguindo o protocolo seqüencial, foi realizada conversão para haste intramedular maciça bloqueada não fresada (UTN $)^{(17)}$ em todos os pacientes. A limpeza cirúrgica e o desdridamento foram realizados segundo os conceitos atuais do tratamento das fraturas expostas.

Segundo a classificação proposta por Johner et al, as fraturas foram divididas em três tipos, segundo o traço de fratura e subdivididas de acordo com o mecanismo de trauma, sendo fratura tipo A: fraturas de traço simples; tipo B: fraturas multifragmentadas em cunha; tipo C: fraturas multifragmentadas complexas. Cada tipo foi subdividido em três grupos, de acordo com o mecanismo de trauma: por torção, por flexão ou por cisalhamento $^{(25)}$.

A classificação de Gustilo et al para fraturas expostas as divide em três graus ${ }^{(20)}$. No nosso estudo incluímos apenas as fraturas expostas grau I (fratura de baixa energia, com lesão de pele menor do que $1 \mathrm{~cm}$, com ferida limpa, sem fragmentação da fratura e com pequena lesão das partes moles) e grau II (fratura de moderada energia, com lesão cutânea entre 1 e $10 \mathrm{~cm}$, com pequena fragmentação óssea e moderada lesão das partes moles) ${ }^{(20)}$.

O fixador externo Pinless ${ }^{\circledR}$ não viola o canal medular, tendo sido concebido para ser utilizado temporariamente no tratamento das fraturas expostas da tíbia ${ }^{(8-13,}$ 18-19,22-24). Ele é constituído por presilhas, rótulas e tubos (figura 1$)^{(8,18)}$. As presilhas prendem-se à cortical externa como um fórceps de redução de osso. A cortical não é penetrada e a cavidade medular permanece fechada (figura 2). As presilhas são construídas de tal forma que a sua fixação na tíbia se faz por pontas afiadas, que se prendem sem atravessar a cortical. As presilhas são de titânio, existentes em tamanhos e geometria diferentes, podendo ser simétricas (grandes ou 

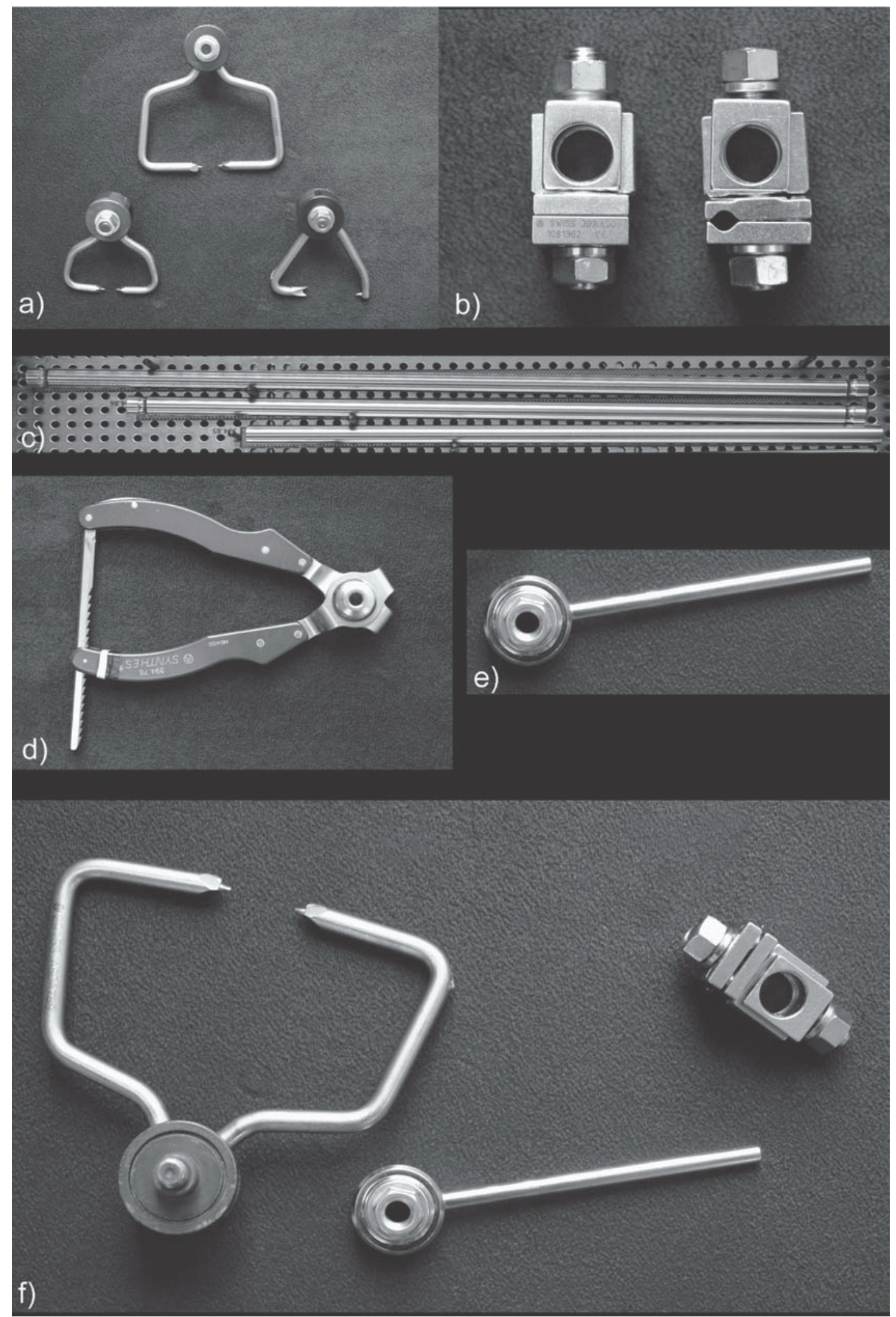


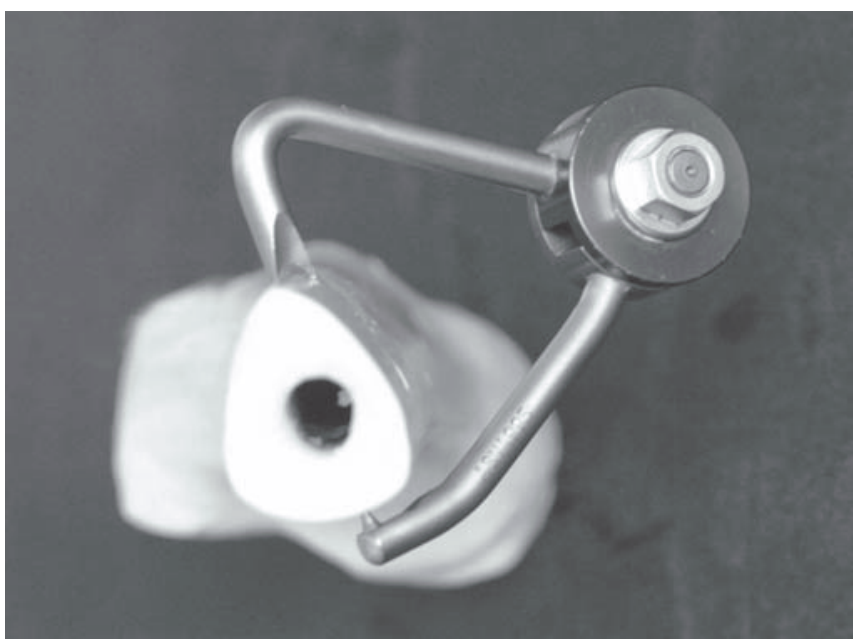

Figura 2

pequenas) e assimétricas (figura 3). As conexões e os tubos são as do fixador externo tubular AO (figuras 1a e $1 b)$.

Para a instalação do Pinless $^{\circledR}$, primeiramente as presilhas das extremidades são colocadas, seguidas das presilhas centrais, assimétricas, implantadas contíguo à fratura, uma proximal e a outra distal ao foco, distando aproximadamente $2 \mathrm{~cm}$ do traço de fratura. Os compartimentos musculares mantêm-se intactos. A ponta bifurcada da presilha assimétrica é colocada na crista tibial e a ponta afilada é posicionada na margem medial. Entre três e cinco movimentos oscilatórios no eixo do trocarte das presilhas simétricas são suficientes para fixá-las. A presilha assimétrica é apertada contra a cortical óssea. Essa presilha assimétrica é desenhada buscando prevenir irritação muscular no terço médio da perna. A pré-carga das presilhas é mantida pelo apertar as alças até a fixação pelo parafuso da articulação central. Antes de apertar o parafuso central, o teste de fixação ( $\mathrm{grab}$ test) é realizado, para assegurar a boa preensão da presilha no osso. A presilha proximal é a simétrica grande e a distal, a simétrica pequena. Um segundo parafuso conectado à haste rotatória do fixador externo tubular AO completa a fixação das presilhas no osso. Colocam-se, então, as rótulas na haste rotatória conectada à presilha e ao tubo do fixador tubular AO. A fratura é reduzida auxiliada por radioscopia em mesa radiotransparente. $\mathrm{O}$ tubo ante-

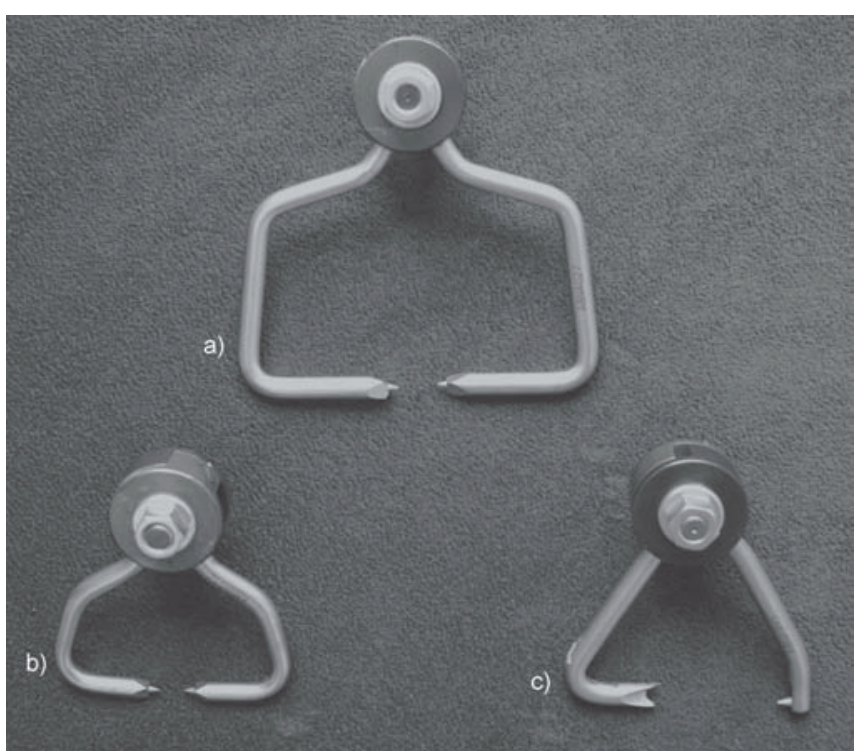

Figura 3

rior é posicionado próximo às rótulas e ao osso, paralelo ao eixo da tíbia, de forma similar à usada para o fixador externo tubular AO. A configuração padrão para o fixador externo Pinless ${ }^{\circledR}$ é: uma presilha simétrica grande proximal, seguida de duas presilhas assimétricas - uma proximal e a outra distal ao foco de fratura - e uma presilha simétrica pequena distal ${ }^{(8,18)}$.

Sendo a redução satisfatória, a subseqüente conversão para haste intramedular não apresenta dificuldades, sendo realizada com o fixador externo Pinless $^{\circledR}$ instalado. Antes do ato cirúrgico para osteossíntese interna, realizamos o planejamento pré-operatório, determinando radiograficamente o diâmetro da cavidade medular, assim como o comprimento da haste com auxílio de transparências. A haste tibial AO não fresada (UTN $)^{(17)}$ é maciça, inicialmente fornecida em liga de titânio (Ti-6Al-7Nb) e em um segundo momento, em aço cirúrgico inoxidável. Independente do material de confecção da haste, o seu formato é o mesmo: triangular com duas secções encontrando-se em ângulo obtuso de $11^{\circ}$ (figura 4). Essa haste existe em dois diâmetros: 8 e 9 $\mathrm{mm}^{(17)}$. Existem quatro orifícios proximais com três possibilidades de bloqueio e três orifícios distais para bloqueios. Na porção proximal, dois orifícios estão no plano coronal e dois em plano oblíquo de $45^{\circ} \mathrm{com}$ o plano coronal (figura 5 ). Na porção 


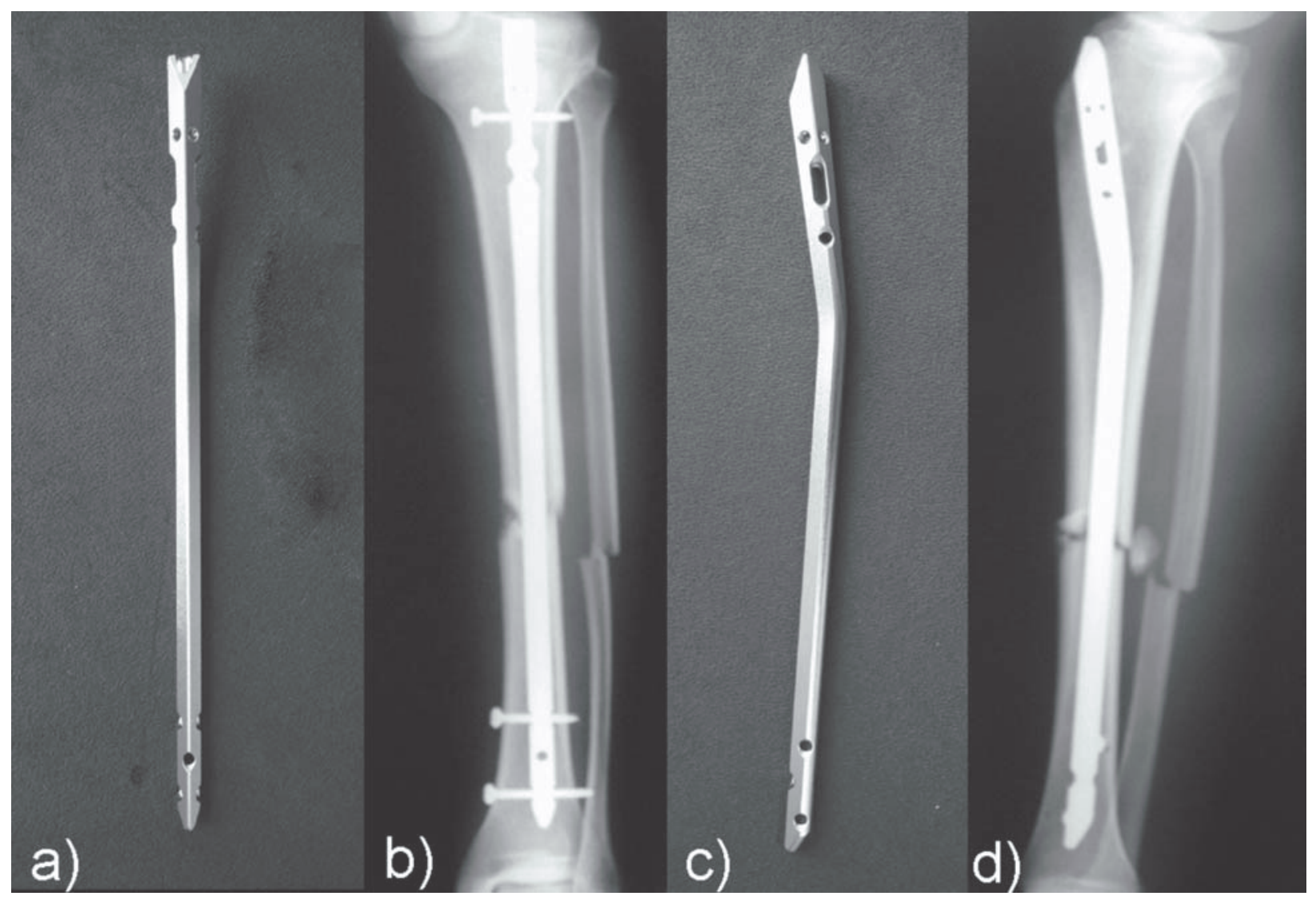

Figura 4

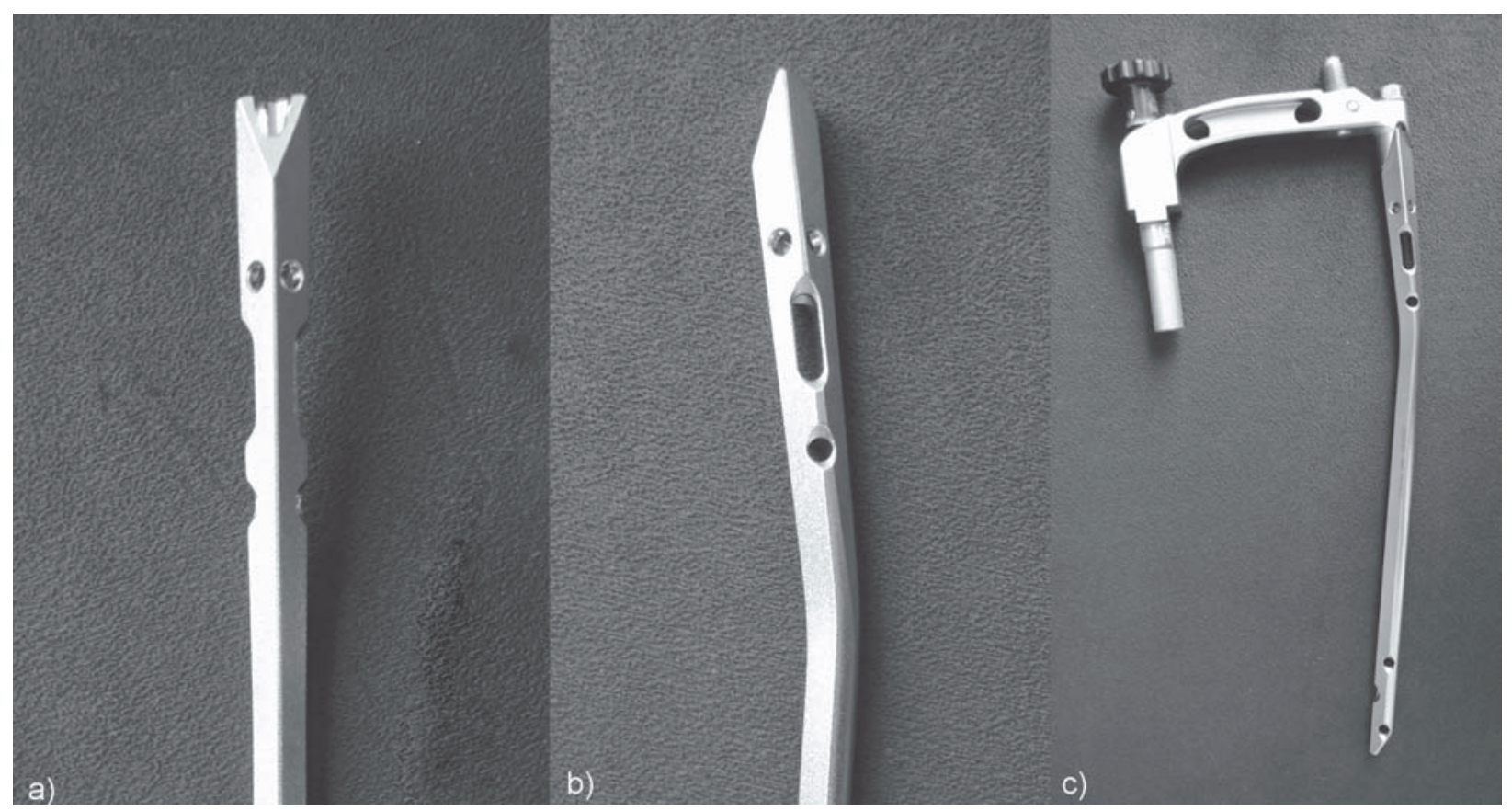

Figura 5

Rev Bras Ortop. 2008;43(1/2):31-40 


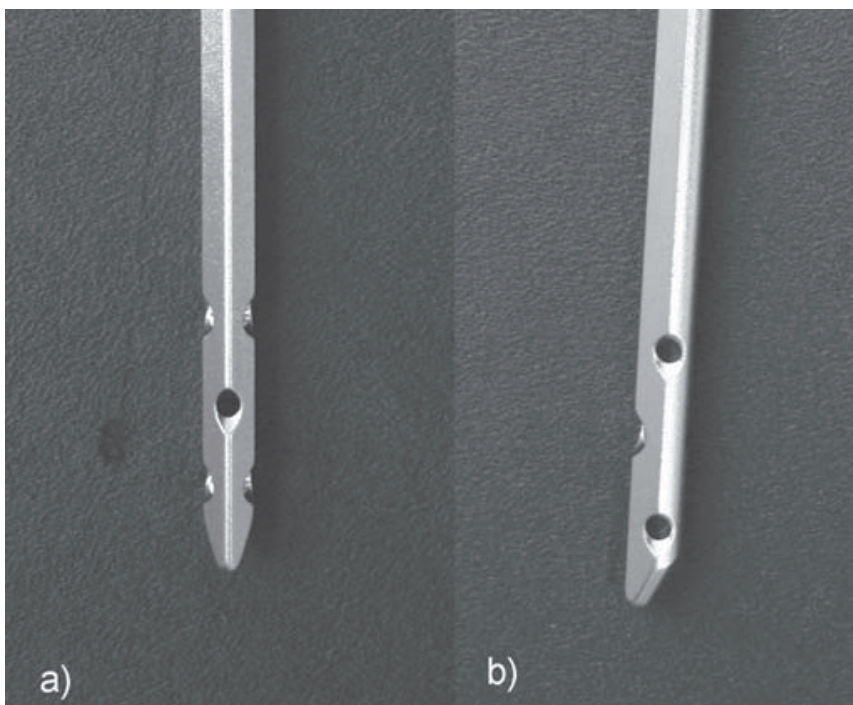

Figura 6

distal, também dois orifícios estão no plano coronal, mas o terceiro, entre os dois coronais, está no plano sagital (figura 6). Os orifícios de bloqueio permitem a passagem de parafusos auto-rosqueantes de $3,9 \mathrm{~mm}$ de diâmetro com asa rasa.

Para a conversão, utilizam-se mesa radiotransparente e radioscopia. A inserção da haste é realizada com o fixador Pinless ${ }^{\circledR}$ instalado na tíbia, por um acesso através do ligamento patelar. A cortical tibial é aberta com um punção. A haste é introduzida com o guia conectado na porção proximal. Na maioria dos casos, a haste pode ser introduzida manualmente. Quando necessário, utiliza-se um martelo. Os parafusos de bloqueio proximal podem ser passados na posição estática ou dinâmica, sendo introduzidos com auxílio do guia proximal. Os parafusos distais são introduzidos a mão livre com auxílio da radioscopia. O correto posicionamento da haste deve ser desde a superfície anterior do planalto tibial até a cicatriz radiográfica da fise de crescimento distal da tíbia.

\section{RESULTADOS}

Todos os 36 pacientes foram submetidos na emergência à limpeza cirúrgica e estabilização com fixador externo Pinless $^{\circledR}$. Após a fixação externa, todos os pacientes foram mantidos internados em enfermaria com carga proibida no membro afetado até conversão para haste intramedular maciça bloqueada não fresada (UTN). Não houve necessidade de novo desbridamento antes da conversão para haste intramedular, mas, quando necessário, novo desbridamento foi realizado durante a conversão para haste intramedular. O tempo médio de fixação com o Pinless ${ }^{\circledR}$ foi de seis dias, variando de três a 22 dias.

Utilizando a classificação proposta por Johner et $a l^{(25)}$, tivemos 12 pacientes $(33,3 \%)$ com fraturas tipo A, $18(50,0 \%)$ com fraturas tipo B e seis $(16,7 \%)$ com fraturas tipo C. Subdividindo as fraturas tipo A (tabela 2 ), dois pacientes $(5,6 \%)$ sofreram fraturas A1; três $(8,3 \%)$, fraturas A2; e sete $(19,4 \%)$, fraturas A3. Subdividindo as fraturas tipo $\mathrm{B}$, dois pacientes $(5,6 \%)$ sofreram fraturas B1; $13(36,1 \%)$, fraturas B2; e três $(8,3 \%)$, fraturas B3. Subdividindo as fraturas tipo C, um paciente $(2,8 \%)$ sofreu fratura $\mathrm{C} 1$; três $(8,3 \%)$, fraturas $\mathrm{C} 2$; e dois $(5,6 \%)$, fraturas $\mathrm{C} 3$.

TABELA 2

Distribuição dos 36 pacientes portadores de fratura exposta da diáfise da tíbia pelo grupo de fratura, segundo a classificação $A^{(23)}$

\begin{tabular}{crr}
\hline Classificação AO & N & (\%) \\
\hline A1 & 2 & 05,6 \\
A2 & 3 & 8,3 \\
A3 & 7 & 19,4 \\
B1 & 2 & 5,6 \\
B2 & 13 & 36,1 \\
B3 & 3 & 8,3 \\
C1 & 1 & 2,8 \\
C2 & 3 & 8,3 \\
C3 & 2 & 5,6 \\
Total & 36 & 100,0 \\
\hline
\end{tabular}

Fonte: SAME Hospital.

Dos 36 pacientes, 32 pacientes $(88,9 \%)$ sofreram fratura associada da fíbula.

Utilizando a classificação de Gustilo et al, para as fraturas expostas, 13 pacientes $(36,1 \%)$ foram classificados como grau I e $23(63,9 \%)$, grau II ${ }^{(20)}$ (tabela 3 ).

Os pacientes que apresentaram fraturas associadas foram submetidos a tratamento cirúrgico das lesões em caráter de urgência, conjuntamente com a fixação externa inicial da fratura exposta da tíbia, com exce- 
TABELA 3

Distribuição dos 36 pacientes portadores de fratura exposta da diáfise da tíbia segundo a classificação de Gustilo e Anderson ${ }^{(10)}$

\begin{tabular}{ccr}
\hline Gustilo e Anderson & N & (\%) \\
\hline I & 13 & 36,1 \\
II & 23 & 63,9 \\
Total & 36 & 100,0 \\
\hline
\end{tabular}

Fonte: SAME Hospital.

ção de um, com fraturas de face e mandíbula tratadas cirurgicamente de forma eletiva após a fixação externa. Em dois pacientes $(5,6 \%)$ ocorreu soltura do fixador externo Pinless ${ }^{\circledR}$ : em uma paciente com fratura tipo A1 e grau I de Gustilo et al ${ }^{(20)}$, a soltura do fixador ocorreu antes da osteossíntese definitiva; em outro paciente com fratura tipo B2 e grau II de Gustilo et al ${ }^{(20)}$ ocorreu soltura durante o procedimento de conversão para osteossíntese definitiva. Em um paciente com fratura tipo C2 e grau II de Gustilo et al ${ }^{(20)}$, o fixador Pinless $^{\circledR}$, já instalado, por estar inadequadamente posicionado, dificultou a introdução da haste. A conversão foi possível em todos os pacientes, não afetando o resultado final da osteossíntese definitiva. Um paciente com fratura tipo C2 e grau II de Gustilo et al $l^{(20)}$ apresentou lesão do nervo fibular superficial. Até a conversão do fixador externo para haste intramedular (11 dias), houve melhora parcial dos sinais da lesão neurológica.

Um paciente com fratura tipo B2 e grau II de Gustilo et $a l^{(20)}$ apresentou síndrome compartimental com instalação no primeiro dia pós-operatório da fixação com Pinless $^{\circledR}$. Foi submetido à fasciotomia na emergência. A incisão cutânea pode ser suturada após cinco dias, ainda com o fixador externo como osteossíntese provisória.

Obtivemos 11,2\% de complicações diretamente relacionadas com a utilização do fixador externo Pinless $^{\circledR}$ : duas solturas do fixador, um fixador inadequadamente posicionado e uma lesão neurológica.

\section{DISCUSSÃO}

Nas fraturas expostas da diáfise da tíbia, a indicação da melhor forma de osteossíntese vai depender da gra- vidade da lesão óssea, do estado das partes moles e da idade do paciente. Devido à pouca cobertura muscular da face medial da tíbia ${ }^{(1,6,14)}$, é freqüiente a associação com extensa lesão de partes moles, como ocorre nas fraturas expostas da tíbia. O método de osteossíntese mais rápido, simples e de aplicação para além da lesão de partes moles, e que ao mesmo tempo é minimamente invasivo e pouco lesivo aos tecidos lesados, é o fixador externo ${ }^{(1,3,6-8,8,11,26)}$.

Como o tempo necessário para a consolidação é prolongado e a solicitação mecânica perdura por longo período nas fraturas expostas da diáfise da tíbia, a fixação externa tende a perder a eficiência até que a resolução definitiva ocorra. Além disso, quando o fixador externo é mantido por muito tempo, existe a possibilidade de contaminação e infecção no trajeto dos pinos e, conseqüentemente, da medular óssea ${ }^{(1,3,6-}$ 15,26). Essa complicação ocorre em até $54 \%$ dos casos, elevando as taxas de infecção profunda após a conversão da fixação externa para osteossíntese interna ${ }^{(7,9-}$ $10,12,14)$.

Considerando o problema, o grupo AO desenvolveu um fixador externo sem pinos de Schanz (Pinless ${ }^{\circledR}$ ), baseado na idéia do fórceps com pontas afiladas, que se prendem na cortical óssea superficial ${ }^{(9-10,13,19)}$. Nesse fixador os elementos de fixação não atingem o canal medular, não havendo, portanto, a contaminação medular $^{(11-13,19,22,27)}$. Dessa forma, a conversão para haste intramedular pode ser realizada com menor risco de infecção ${ }^{(9-12,24,27)}$. Entretanto, como não é aplicado nas duas corticais, a estabilidade do fixador externo Pinless $^{\circledR}$ é menor e, por isso, sua utilização como osteossíntese definitiva das fraturas da diáfise da tíbia não deve ser adotada, mas, sim, como estabilizador temporário, impondo, mais tarde, a conversão para osteossíntese interna ${ }^{(10-11,18,22-23)}$.

A segunda vantagem do fixador externo Pinless ${ }^{\circledR}$ é a simplicidade na aplicação, pois não necessita de perfurador elétrico ${ }^{(9-10,12-13,18,22)}$. Os tubos e rótulas utilizados na montagem do Pinless ${ }^{\circledR}$ são as empregadas no fixador externo tubular AO. A terceira vantagem é a possibilidade de corrigir a redução em qualquer direção, mesmo após instalado(22), algo impossível nas montagens lineares. 
Outra vantagem do fixador externo Pinless $^{\circledR}$ é a possibilidade da conversão para haste intramedular com o fixador externo mantendo a redução da fratura. Por ser extramedular, não precisa ser retirado ao longo da conversão(9-13).

Estudos mecânicos com o fixador externo Pinless ${ }^{\circledR}$ mostraram perda de $28 \%$ da força de preensão da presilha, com maior intensidade nos primeiros 20 dias; em cinco semanas de carga funcional sobre as presilhas, tem-se $72 \%$ da força inicial do mesmo ${ }^{(8,10)}$. Biologicamente, observaram-se alterações ósseas em apenas $1,2 \mathrm{~mm}$ de profundidade na cortical óssea ${ }^{(8)}$. A partir dessas observações, recomenda-se o uso do fixador externo Pinless ${ }^{\circledR}$ para a fixação estável temporária das fraturas da tíbia, visando a conversão segura para haste intramedular ${ }^{(7)}$. Como a conversão do fixador externo para haste intramedular deve ocorrer no máximo em 14 dias, a perda de $28 \%$ na força de preensão da presilha do Pinless $^{\circledR}$ não tem significado clínico ${ }^{(13)}$.

A indicação do uso de hastes maciças para o tratamento das fraturas expostas evita os efeitos deletérios sobre a vascularização endosteal em conseqüência da fresagem do canal medular ${ }^{(1,6,15)} \mathrm{e}$ da contaminação endosteal inevitável do foco de fratura. Por ser maciça, elimina o espaço morto central do implante, diminuindo, assim, o risco de infecção ${ }^{(7,17)}$.

$\mathrm{Na}$ revisão da literatura, encontramos poucos relatos clínicos sobre a fixação imediata de fraturas expostas da diáfise da tíbia com o Pinless $^{\circledR}$, seguida de conversão para haste intramedular maciça bloqueada não fresada ${ }^{(11-12,23-24,27)}$.

No nosso estudo, o tempo médio de permanência com o fixador externo Pinless ${ }^{\circledR}$ foi de seis dias, estando dentro do considerado ideal para a fixação temporária com fixador externo. Dos trabalhos levantados sobre a fixação com Pinless ${ }^{\circledR}$, o tempo médio de permanência com o fixador variou de oito a 36 dias $^{(11,23-}$ 24,27). O tempo máximo relatado é de 30 semanas $^{(12)}$. Na nossa casuística, o tempo máximo de permanência com o Pinless ${ }^{\circledR}$ foi de 22 dias. Estudos mostram predominância do sexo masculino, variando de $62 \%$ a $89 \%{ }^{(23-24)}$. Encontramos, em nossa casuística, incidência de $89 \%$ para o sexo masculino.
Da análise da literatura sobre a fixação de fraturas expostas da diáfise da tíbia com Pinless ${ }^{\circledR}$, pudemos observar que nossa casuística é semelhante à de outros autores, havendo gravidade maior que a de outros trabalhos ${ }^{(11-12,23-24,27)}$, por ocorrer predomínio de fraturas expostas grau II de Gustilo et al(20) e do tipo B da classificação de Johner $e t$ al ${ }^{(25)}$.

Encontramos poucas complicações; todas elas não comprometeram o resultado da conversão, o que é compartilhado por outros autores ${ }^{(11-12,23-24)}$. Entretanto, Schütz et al obtiveram resultados insatisfatórios ${ }^{(24)}$. Thomas et al ${ }^{(13)}$ consideram a aplicação do fixador externo Pinless ${ }^{\circledast}$ difícil e perigosa, pois coloca em risco estruturas anatômicas importantes, sugerindo incidência elevada de complicações com sua utilização, fato que não foi encontrado por nós e por outros auto$\operatorname{res}^{(8,10,12,23-24,27)}$.

Em 8,3\% dos casos tivemos dificuldades com a conversão do fixador externo Pinless ${ }^{\circledast}$ para haste intramedular bloqueada não fresada. Apesar das dificuldades encontradas, em nenhum paciente foi impossível a conversão para haste intramedular como programado, semelhante ao que é relatado na literatura ${ }^{(11-12,23-}$ ${ }^{24,27)}$. Devemos ressaltar que as dificuldades encontradas na conversão apenas alongaram o procedimento ${ }^{(23)}$.

Outra complicação é a ocorrência de lesão do nervo fibular superficial, ocorrido em um paciente (no 2) da nossa série e em $50 \%$ dos casos em outro estudo ${ }^{(11)}$. Essa complicação provavelmente foi determinada pelo braço lateral da presilha distal do Pinless ${ }^{\circledR}$.

Contrariamente aos autores que relataram ser o Pinless $^{\circledR}$ destituído de superioridade significativa sobre os outros métodos, observamos vantagens, pois obtivemos baixa incidência de complicações (menor do que a da literatura), sem infecção local, sem necessidade de mudança de procedimento devido a soltura ou má colocação desse fixador externo ${ }^{(11-12,23-24,27)}$.

Como o nosso estudo avalia apenas a fixação com o Pinless $^{\circledR}$, não podemos avaliar a incidência final de infecção óssea, uma vez que o nosso tempo de seguimento é muito pequeno, no máximo de 22 dias; esse foi o tempo da fixação externa com o Pinless ${ }^{\circledR}$. Com os bons resultados observados, estamos prosseguindo o estudo para avaliar os resultados finais após a con- 
versão da fixação externa com Pinless ${ }^{\circledR}$ para haste intramedular maciça bloqueada não fresada.

As principais desvantagens do protocolo de procedimento seqüencial para o tratamento das fraturas expostas da diáfise da tíbia, consistindo na fixação externa imediata seguida por conversão para haste intramedular, são a necessidade de pelo menos dois procedimentos cirúrgicos e o período de internação hospitalar.

\section{CONCLUSÃO}

Da análise dos nossos resultados, podemos concluir que o fixador externo não transfixante é eficaz como osteossíntese provisória das fraturas expostas graus I e II da diáfise da tíbia, com pequena incidência de complicações, facilitando a conversão para osteossíntese intramedular.

\section{REFERÊNCIAS}

1. Reis FB, Fernandes HJA, Belloti JC. Existe evidência clínica, baseada em estudo de metanálise, para a melhor opção de osteossíntese nas fraturas expostas da diáfise da tíbia? Rev Bras Ortop. 2005;40(5):223-8.

2. Cunha FM, Braga GF, Drumond Jr SN, Figueiredo CTO. Epidemiologia de 1.212 fraturas expostas. Rev Bras Ortop. 1998; 33(6):451-6.

3. Ferreira JCA. Fraturas da diáfise dos ossos da perna. Rev Bras Ortop. 2000;35(10):375-83.

4. Grecco MAS, Prado Jr I, Rocha MA, Barros JW. Estudo epidemiológico das fraturas diafisárias de tíbia. Acta Ortop Bras. 2002; 10:10-7.

5. Grütter R, Cordey J, Bühler M, Johner R, Regazzoni P. Epidemiology of diaphyseal fractures of the tibia. Injury. 2000; 31(Suppl 3):C64-7.

6. Bhandari M, Guyatt GH, Swiontkowski MF, Schemitsch EH. Treatment of open fractures of the shaft of the tibia - a systematic overview and meta-analysis. J Bone Joint Surg Br. 2001;83(1):62-8.

7. Paccola CAJ. Fraturas expostas. Rev Bras Ortop. 2001;36(8): 283-91.

8. Stene GM, Frigg R, Schlegel U, Swiontkowski M. Biomechanical evaluation of the "Pinless" external fixator. Injury. 1992;23(Suppl 3):S9-27.

9. Swiontkowski MF. The Pinless fixator - part II. Injury. 1994;25 (Suppl 3):S-C1-2.

10. Remiger AR. Mechanical properties of the Pinless external fixator on human tibiae. Injury. 1992;23(Suppl 3):S28-43.
11. Winkler H, Hochstein P, Wentzensen A. Experience with the "Pinless" fixator in the treatment of fractures of the lower leg. Injury. 1994;25(Suppl 3):S-C8-14.

12. Schütz M, Südkamp N, Frigg R, Hoffman R, Stöckle U, Hass N. "Pinless" external fixation - indications and preliminary results in tibial shaft fractures. Clin Orthop Relat Res. 1998; (347):35-42.

13. Thomas SR, Giele H, Simpson AH. Advantages and disadvantages of Pinless external fixator. Injury. 2000;31(10): 805-9.

14. Gershuni DH, Halma G. The AO external skeletal fixator in the treatment of severe tibial fractures. J Trauma. 1983;23(11):98690.

15. Giannoudis PV, Papakostidis C, Roberts C. A review of the management of open fractures of the tibia and femur. J Bone Joint Surg Br. 2006;88(3):281-9.

16. Melcher GA, Ryf C, Leutenegger A, Rüedi T. Tibial fractures treated with the AO unreamed tibial nail. Injury. 1993;24(6): 407-10.

17. Weller S, Höntsch D. Medulllary nailing of femur and tibia. In: . Manual of internal fixation. $3^{\text {rd }}$ ed. New York: Springer; 1992. p. 291-365.

18. Frigg R. The development of the Pinless external fixator: from the idea to the implant. Injury. 1992;23(Suppl 3):S3-8.

19. Perren SM. Pinless fixation - Part I: introduction. Injury. 1992; 23(Suppl 1):S1-2.

20. Gustilo RB, Anderson JT. Prevention on infection in the treatment of one-thousand and twenty-five open fractures of long bones. J Bone Joint Surg Am. 1976;58(4):453-8.

21. Balbachevsky D, Belloti JC, Martins CVE, Fernandes HJA, Faloppa F, Reis FB. Como são tratadas as fraturas expostas da tíbia no Brasil? Estudo transversal. Acta Ortop Bras. 2005;13: 229-32.

22. Hass N, Schütz M, Wagenitz A, Krettek C, Südkamp N. Routine application of the Pinless external fixator. Injury. 1994;25 (Suppl 3):S-C3-7.

23. Remiger AR, Magerl F. The "Pinless" external fixator relevance of experimental results in clinical applications. Injury. 1994;25:(Suppl 3):S-C15-29.

24. Schütz M, Bühler M, Swiontkowski MF, Matter P. Documentation - Pinless external fixator: prospective study. Injury. 1994;25(Suppl3):S-C34-7.

25. Johner R, Wruhs O. Classification of tibial shaft fractures and correlation with results after rigid internal fixation. Clin Orthop Relat Res. 1983;(178):7-25.

26. Lourenço PRB, Franco JS. Atualização no tratamento das fraturas expostas. Rev Bras Ortop. 1998;33(6):436-46.

27. Barbu D, Putineanu D, Niculescu P, Toma C. The value of external Pinless fixator in open tibial fractures. J Bone Joint Surg Br. 2004;86(Suppl III):358. 